\title{
HUBUNGAN DUKUNGAN ORANG TUA DENGAN PRESTASI BELAJAR SISWA KELAS VIII SLTP NEGERI 6 YOGYAKARTA
}

\author{
Rita Dwi Pratiwi \\ Program Studi S1 Keperawatan \\ Sekolah Tinggi Ilmu Kesehatan Widya Dharma Husada Tangerang \\ Email: ritadwipratiwi@wdh.ac.id
}

\begin{abstract}
ABSTRAK
Latar Belakang: Pencapaian prestasi belajar siswa pada hakikatnya dipengaruhi dari internal individu yaitu dari kondisi fisik dan psikologis siswa maupun eksternal individu yaitu dari kondisi non sosial dan sosial yang bisa datang dari orang tua. Orang tua adalah salah satu faktor eksternal yang penting dalam kelangsungan pendidikan anaknya melalui pemberian dukungan informasional, instrumental, emosi, penilaian dan penghargaan. Sampai saat ini masih ada kontroversi dalam penelitian mengenai dukungan orang tua dalam pencapaian prestasi belajar. Tujuan Penelitian: Untuk mengetahui hubungan dukungan orang tua dengan prestasi belajar siswa kelas VIII di SLTP Negeri 6 Yogyakarta. Metode: Jenis penelitian ini adalah Survey Analytical korelasional non eksperimental dengan menggunakan pendekatan kuantitatif dan rancangan cross sectional. Sampel penelitian adalah siswa kelas VIII di SLTP Negeri 6 Yogyakarta yang memenuhi kriteria inklusi dan eksklusi dengan metode total sampling. Pengambilan data penelitian dengan kuesioner dukungan orang tua dan dokumentasi nilai rapor siswa. Hasil: Hasil penelitian menunjukkan bahwa dukungan orang tua mayoritas tinggi sebanyak 142 siswa (86,6\%). Sedangkan prestasi belajar mayoritas cukup sebanyak $86(52,4 \%)$. Hasil analisis bivariat dengan Uji $a$ dengan tingkat kepercayaan $99 \%$ dihasilkan koefisien korelasi (r) sebesar 0,271 dan signifikasi $(p)=0,000$. Hal ini menunjukkan ada hubungan yang bermakna antara dukungan orang tua dengan prestasi belajar siswa kelas VIII di SLTP Negeri 6 Yogyakarta. Kesimpulan: Ada hubungan lemah dan positif antara dukungan orang tua dengan prestasi belajar siswa kelas VIII di SLTP Negeri 6 Yogyakarta.

Kata kunci: Dukungan orang tua, prestasi belajar, siswa SMP kelas VIII
\end{abstract}

\begin{abstract}
Background: Academic achievement is the result achieved through the process of learning. Academic achievement of students is basically affected by internal as well external factors of individuals. Internal factor is viewed from physical and psychological condition of students, whereas external factor is viewed from nonsocial and social condition that may come from parents. Parents belong to external factor that is essential for the continuation of children's education through the support in information, instrument, emotion, evaluation and reward. Until today there are controversies over parental support in academic achievement.

Objective: To identify association between parental support and academic achievement of grade VIII students of SLTP Negeri 6 Yogyakarta. Method: This was a non-experimental analytical correlational survey that used quantitative approach and cross sectional design. Samples were students of grade VIII at SLTP Negeri 6 Yogyakarta that fulfilled inclusion and exclusion criteria with total sampling method. Data were obtained through questionnaire of parental support and school report document of students. Result: The result of the study showed that the majority of students (142 students or 86.6\%) got parental support and the majority of students (86 students or 52.4\%) had academic achievement. The result of bivariate Spearman Rank test at significance $99 \%$ showed correlation coefficient $(R)$ was 0.271 and significance was $(p)=0.000$. This indicated that there was significant association between parental support and academic achievement of students at grade VIII of SLTP Negeri 6 Yogyakarta. Conclusion: There was weak and positive association between parental support and academic achievement of students at grade VIII of SLTP Negeri 6 Yogyakarta.
\end{abstract}

Keywords: parental support, academic achievement, students at grade VIII of Junior High School 


\section{LATAR BELAKANG}

Belajar adalah interaksi seorang secara langsung terhadap objek dan merupakan proses dari perkembangan hidup manusia. Prestasi belajar adalah hasil dari proses belajar (Ahmadi dan Supriono, 2011). Prestasi belajar siswa adalah kemampuan aktual yang diukur langsung melalui suatu prestasi belajar dalam bentuk skor rapor yang diberikan setiap akhir semester atau triwulan sebagai hasil kemampuan yang telah dimiliki siswa (Winkel, 2007).

Faktor yang mempengaruhi prestasi belajar berasal dari faktor eksternal terdiri dari faktor non sosial dan faktor sosial dan dari internal individu yaitu faktor fisik dan psikologis (Ahmadi dan Supriono, 2013). Faktor sosial yang mempengaruhi prestasi belajar salah satunya dari orang tua. Orang tua adalah orang yang pertama bertanggung jawab terhadap pendidikan anaknya (Hasbullah, 2012). Dukungan orang tua dalam pencapaian prestasi belajar anak sangatlah penting, yang meliputi dukungan emosional, informasional, instrumental, penilaian dan penghargaan (Friedman, 2010). Kasih sayang dari orang tua, perhatian atau penghargaan akan menimbulkan mental yang sehat bagi anak. Kekurangan kasih sayang, sikap keras dan kejam akan menimbulkan emosinal insequrity sehingga anak akan mengalami kesulitan

belajar. Oleh karena itu diperlukan bimbingan belajar dari orang tua agar sikap dewasa dan tanggung jawab tumbuh pada diri anak. Pekerjaan orang tua, pendidikan orang tua dan jumlah gaji orang tua juga akan mempengaruhi prestasi belajar anaknya. Keadaan ekonomi keluarga yang terpenuhi dari pekerjaan orang tua mempengaruhi kebutuhan belajar anak yang terkait dengan prestasi belajar (Ahmadi dan Supriono, 2013).

Sebanyak $48 \%$ orang tua senang memonitor dan ikut dalam proses pendidikan anak, $42 \%$ orang tua tidak memantau perkembangan anak di sekolah, dan sebanyak $10 \%$ orang tua tidak memberi jawaban mengenai hal tersebut (Peters dkk, 2007). Orang tua berperan penting dalam membantu anak bersekolah dan dalam pencapaian prestasi belajar, hal ini dikarenakan orang tua dapat berkoordinasi dengan pendidik dan memantau perkembangan anak di sekolah melalui guru di sekolah (Depdiknas, 2008). Di Indonesia angka putus sekolah SMP cukup tinggi yaitu 0,27\% dari jumlah anak SMP di Indonesia (Sulastri, 2007). Siswa SMP mayoritas berada pada tahap perkembangan remaja awal antara umur 12-15 tahun dan berada pada status interim yang sebagian kehidupannya diberikan orang tua dan sebagian hasil usahanya sendiri. Tahap remaja awal ini memiliki kecenderungan untuk memisahkan diri dengan orang tua dalam hal hubungan 
emosional. Hal ini menyebabkan remaja mudah untuk mengikuti arus perkembangan zaman dan mudah terbawa ke hal-hal yang negatif apabila tidak memiliki prinsip diri yang jelas terutama dalam hal pendidikan (Syah, 2008). Masa remaja secara ekonomik masih tergantung dengan orang tua baik dalam proses belajar di sekolah maupun kebutuhan lainnya (Sulastri, 2007).

Berdasarkan studi pendahuluan di SMP Negeri 6 Yogyakarta melalui wawancara ke 10 siswa kelas VIII didapatkan adanya fenomena perbedaan pola dukungan orang tua kepada anak-anak dalam proses pembelajaran, berbagai keragaman latar belakang sosial ekonomi keluarga murid dari kalangan menengah ke bawah sampai kalangan menengah ke atas. Terdapat perbedaan orientasi prestasi belajar antara guru dan orang tua dengan murid kelas VIII tersebut. Orang tua murid dan guru lebih orientasi terhadap prestasi akademik tetapi siswa kelas VIII lebih antusias ke olahraga terutama basket. Selain itu dari hasil wawancara dan penyebaran kuesioner kepada 26 siswa baik kelas VII, VIII dan IX didapatkan fenomena sebanyak 12 anak mengatakan bahwa terdapat pemaksaan dari orang tua agar anak selalu belajar dan mendapatkan nilai yang terus naik dan apabila nilai turun terdapat hukuman kepada siswa. Oleh karena itu peneliti bermaksud melakukan penelitian mengenai hubungan dukungan orang tua dalam pencapaian prestasi belajar siswa SMP.

\section{METODE PENELITIAN}

Jenis penelitian ini adalah survey analytical korelasional non eksperimental dengan menggunakan pendekatan kuantitatif dan menggunakan rancangan cross sectional (Sugiyono, 2016). Penelitian dilakukan di SMP Negeri 6 Yogyakarta dengan responden seluruh siswa kelas VIII SMP Negeri 6 Yogyakarta yang berjumlah 164 responden yang menggunakan menggunakan metode total sampling. Analisis bivariat antara dukungan orang tua dengan prestasi belajar siswa kelas VIII SMP Negeri 6 Yogyakarta menggunakan uji Spearman Rank (Dahlan, 2014). 


\section{HASIL DAN PEMBAHASAN}

\section{Karakteristik Responden}

Tabel 1. Distribusi Frekuensi Karakteristik Responden Siswa kelas VIII di SMP Negeri 6

\begin{tabular}{clcc}
\multicolumn{2}{c}{ Yogyakarta $(\mathrm{n}=164)$} & & \\
\hline No & \multicolumn{1}{c}{ Karakteristik } & Jumlah $(\mathrm{n})$ & Persentase $(\%)$ \\
\hline 1 & Kelas & 30 & 18,3 \\
& VIII A & 26 & 15,9 \\
& VIII B & 27 & 16,5 \\
& VIII C & 26 & 15,9 \\
& VIII D & 26 & 15,9 \\
& VIII E & 29 & 17,7 \\
& VIII F & & \\
\hline 2 & Jenis Kelamin & 75 & 45,7 \\
& Laki-laki & 89 & 54,3 \\
& Perempuan & & \\
\hline 3 & Usia & 3 & 1,8 \\
& 12 tahun & 53 & 32,3 \\
& 13 tahun & 104 & 63,4 \\
& 14 tahun & 4 & 2,4 \\
15 tahun & & \\
\hline 4 & IQ & 14 & 8,5 \\
& Sedang (85-99) & 90 & 54,9 \\
& Pandai (100-114) & 59 & 36,0 \\
& Cerdas (115-129) & 1 & 0,6 \\
\hline
\end{tabular}
Sumber:

a. Data kelas, jenis kelamin dan usia didapatkan dari pengolahan data primer

b. Data karakteristik IQ responden didapatkan dari sumber data sekunder

Tabel 1 menunjukkan karakteristik responden mayoritas berjenis kelamin wanita $(54,3 \%)$. Karakteristik usia responden menunjukkan bahwa siswa kelas VIII berada di rentang tahapan remaja awal yaitu antara umur 12 tahun15 tahun. Sebagian besar responden berusia 14 tahun $(63,4 \%)$. Karakteristik IQ (Intelegensi) responden menunjukkan bahwa responden sebagian besar memiliki intelegensi pandai $(54,9 \%)$. Rentang usia remaja awal ini berada pada periode transisi yang lepas dari perode kanakkanak dan batas menuju pencapaian ke arah kedewasaan dan berada pada status interim (kehidupan sebagian diberikan oleh orang tua dan sebagian oleh dirinya (Friedman, 2012). Intelegensi memiliki pengaruh yang besar terhadap belajar. Intelegensi (IQ) adalah salah satu faktor internal individu yang berupa aspek psikologis yang dapat mempengaruhi prestasi belajar siswa (Syah, 2008., Dalyono, 2015). 


\section{Karakteristik Orang Tua Siswa Kelas VIII}

Tabel 2. Distribusi Frekuensi Daftar Gaji Orang Tua Responden Siswa kelas VIII di SMP Negeri 6 Yogyakarta $(n=164)$

\begin{tabular}{|c|c|c|}
\hline Karakteristik daftar gaji & Jumlah (n) & Presentase $(\%)$ \\
\hline$<\operatorname{Rp} 500.000,00$ & 12 & 7,3 \\
\hline$\leq \mathrm{Rp} 1.000 .000,00$ & 27 & 16,5 \\
\hline$>\operatorname{Rp} 1.000 .000,00 \leq \mathrm{Rp} 2.000 .000,00$ & 45 & 27,4 \\
\hline$>\operatorname{Rp} 2.000 .000,00 \leq \operatorname{Rp} 3.000 .000,00$ & 20 & 12,2 \\
\hline$>\operatorname{Rp} 3.000 .000,00 \leq \operatorname{Rp} 4.000 .000,00$ & 20 & 12,2 \\
\hline$>\operatorname{Rp} 4.000 .000,00 \leq \operatorname{Rp} 5.000 .000,00$ & 24 & 14,6 \\
\hline$>\operatorname{Rp} 5.000 .000,00$ & 16 & 9,8 \\
\hline
\end{tabular}

\section{Sumber: Data Sekunder}

Tabel tersebut menunjukkan bahwa jumlah gaji orang tua responden paling banyak pada rentang gaji lebih dari $\mathrm{Rp}$ $1.000 .000,00 \leq \operatorname{Rp} 2.000 .000,00(27,4 \%)$. Jumlah gaji tersebut berkaitan dengan bentuk dukungan material atau instrumental yang akan diberikan oleh orang tua terhadap anaknya terkait dengan proses pendidikan. Keluarga yang berpenghasilan rendah, tidak dapat membeli buku-buku untuk anaknya sehingga anak kurang membaca dan prestasi belajar anaknya kurang memuaskan (Legawati, 2005., Friedman, 2010). Status sosial ekonomi memiliki hubungan yang signifikan dengan prestasi belajar (Sulastri, 2007).

Tabel 3. Distribusi Frekuensi Pendidikan Orang Tua Responden Siswa kelas VIII di SMP Negeri 6 Yogyakarta( $(n=164)$

\begin{tabular}{lcccc}
\hline \multicolumn{1}{c}{$\begin{array}{c}\text { Karakteristik } \\
\text { Pendidikan Orang Tua }\end{array}$} & \multicolumn{2}{c}{ Ayah } & \multicolumn{2}{c}{ Ibu } \\
\cline { 2 - 5 } & $\mathrm{F}$ & $(\%)$ & $\mathrm{F}$ & $(\%)$ \\
\hline SD & 9 & 5,5 & 13 & 7,9 \\
SMP & 9 & 5,5 & 6 & 3,7 \\
SLTA & 44 & 26,8 & 49 & 29,9 \\
Diploma & 19 & 11,6 & 27 & 16,5 \\
S1 & 62 & 37,8 & 61 & 37,2 \\
S2 & 18 & 11,0 & 5 & 3,0 \\
S3 & 3 & 1,8 & 3 & 1,8 \\
\hline \multicolumn{1}{r}{ Total } & 164 & $100 \%$ & 164 & $100 \%$ \\
\hline
\end{tabular}

Sumber : Data Sekunder

Tabel tersebut menunjukkan bahwa tingkat pendidikan ayah responden mayoritas S1 $(37,8 \%)$ dan tingkat pendidikan ibu responden mayoritas S1 (37,2 \%). Tingkat Pendidikan memadai dari orang tua responden berkaitan dengan wawasan dan kemampuan orang tua dalam memberi solusi terkait dengan proses belajar anak (Hurlock, 2013) . 


\section{ANALISIS UNIVARIAT.}

\section{DUKUNGAN ORANG TUA}

Tabel 4. Distribusi Frekuensi Variabel Dukungan Orang Tua Siswa Kelas VIII SMP Negeri 6 Yogyakarta $(n=164)$

\begin{tabular}{lccccccl}
\hline Dukungan & \multicolumn{9}{c}{ KELAS } & & \multirow{2}{*}{ Total } \\
\cline { 2 - 5 } Orang tua & VIIIA & VIIIB & VIIIC & VIIID & VIIIE & VIIIF & \\
\hline Rendah & 1 & 0 & 0 & 10 & 0 & 0 & 11 \\
& $(9,1 \%)$ & $(0 \%)$ & $(0 \%)$ & $(90,9 \%)$ & $(0 \%)$ & $(0 \%)$ & $100 \%)$ \\
Sedang & 1 & 3 & 3 & 1 & 2 & 1 & 11 \\
& $(9,1 \%)$ & $(27,3 \%)$ & $(27,3 \%)$ & $(9,1 \%)$ & $(18,2 \%)$ & $(9,1 \%)$ & $100 \%$ \\
& & & & & & & $14 \%$ \\
Tinggi & 28 & 23 & 24 & 15 & 24 & 28 & $(86,6 \%)$ \\
& $19,7 \%$ & $16,2 \%$ & $16,9 \%$ & $10,6 \%$ & $16,9 \%$ & $19,7 \%$ & $100 \%$ \\
\hline Total & 30 & 26 & 27 & 26 & 26 & 29 & 164 \\
& $100 \%$ & $100 \%$ & $100 \%$ & $100 \%$ & $100 \%$ & $100 \%$ & $100 \%$ \\
\hline
\end{tabular}

Sumber : Data Primer

Tabel 4 menunjukkan bahwa dukungan orang tua tertinggi pada kelas VIII A dan VIII F (19,7 \%). Siswa kelas VIII di SMP Negeri 6 Yogyakarta mayoritas memiliki dukungan orang tua tinggi $(86,6 \%)$.

Dukungan orang tua yang berupa instrumental/material, penghargaan danpenilaian seperti bimbingan dan a.Prestasi belajar nasehat, dukungan emosional seperti seperti keamanan dan kedamaian serta dukungan informasional seperti petunjuk dalam penyelesaian masalah pendidikan anak yang dapat mempengaruhi prestasi belajar anaknya (Friedman, 2010).

Tabel 5. Distribusi Frekuensi Variabel Prestasi Belajar Siswa Kelas VIII di SMP

\begin{tabular}{|c|c|c|c|c|c|c|c|}
\hline \multirow{2}{*}{$\begin{array}{l}\text { Prestasi } \\
\text { Belajar }\end{array}$} & \multirow[b]{2}{*}{ VIII A } & \multirow[b]{2}{*}{ VIII B } & \multicolumn{2}{|c|}{ Kelas } & \multirow[b]{2}{*}{ VIII E } & \multirow[b]{2}{*}{ VIII F } & \multirow{2}{*}{ Total } \\
\hline & & & VIII C & VIII D & & & \\
\hline Kurang & $\begin{array}{c}1 \\
(1,7 \%)\end{array}$ & $\begin{array}{c}7 \\
(12,1 \%)\end{array}$ & $\begin{array}{c}16 \\
(27,6 \%)\end{array}$ & $\begin{array}{c}14 \\
(24,1 \%)\end{array}$ & $\begin{array}{c}10 \\
(17,2 \%)\end{array}$ & $\begin{array}{c}10 \\
(17,2 \%)\end{array}$ & $58(35,4 \%)$ \\
\hline Cukup & $\begin{array}{c}16 \\
(18,6 \%)\end{array}$ & $\begin{array}{c}17 \\
(19,8 \%)\end{array}$ & $\begin{array}{c}10 \\
(11,6 \%)\end{array}$ & $\begin{array}{c}10 \\
(11,6 \%)\end{array}$ & $\begin{array}{c}16 \\
(18,6 \%)\end{array}$ & $\begin{array}{c}17 \\
(19,8 \%)\end{array}$ & $86(52,4 \%)$ \\
\hline Baik & $\begin{array}{c}13 \\
(65 \%)\end{array}$ & $\begin{array}{c}2 \\
(10 \%)\end{array}$ & $\begin{array}{c}1 \\
(5 \%)\end{array}$ & $\begin{array}{c}2 \\
(10 \%)\end{array}$ & $\begin{array}{c}0 \\
(0 \%)\end{array}$ & $\begin{array}{c}2 \\
(10 \%)\end{array}$ & $20(12,2 \%)$ \\
\hline Total & 30 & 26 & 27 & 26 & 26 & 29 & 164 \\
\hline
\end{tabular}

Sumber : Data Sekunder 
Tabel 5 menunjukkan prestasi belajar dengan kategori baik paling banyak pada kelas VIII A (65\%). Hasil penelitian menunjukkan bahwa prestasi belajar siswa kelas VIII di SMP negeri 6 Yogyakarta mayoritas kategori cukup $(52,4 \%)$.

Prestasi belajar yang dicapai individu merupakan hasil interaksi antara faktor internal individu maupun faktor eksternal individu (Winkel, 2007). Faktor intern yang dimaksud dilihat dari aspek psikologis yang meliputi kecerdasan, minat, bakat, motivasi dan dari aspek fisiologis individu mencakup keadaan organ tubuh individu yang mempengaruhi

\section{Analisis Bivariat}

semangat intensitas siswa dalam megikuti pelajaran di sekolah. Faktor eksternal yang mempengaruhi prestasi belajar meliputi lingkungan non sosial yang meliputi keadaan sekolah, rumah tinggal, cara belajar dan waktu belajar yang digunakan oleh siswa. Lingkungan sosial yang mempengaruhi prestasi belajar siswa meliputi keadaan keluarga misalnya suasana rumah yang akan mempengaruhi konsentrasi anak dalam belajar dan keadaan ekonomi keluarga. Belajar memerlukan bimbingan dari orang tua agar sikap dewasa dan tanggung jawab belajar dapat tumbuh di diri anak (Ahmadi dan Supriyono, 2013).

\section{a. Hubungan Dukungan Orang Tua dengan Prestasi Belajar Siswa Kelas VIII di SMP}

\section{Negeri 6 Yogyakarta}

Tabel 6. Hubungan Dukungan Orang Tua dengan Prestasi Belajar Siswa Kelas VIII di SMP Negeri 6 Yogyakarta $(n=164)$

\begin{tabular}{|c|c|c|c|c|c|c|}
\hline \multirow{2}{*}{$\begin{array}{l}\text { Dukungan } \\
\text { Orang Tua }\end{array}$} & \multicolumn{3}{|c|}{ Nilai Rapor } & \multirow{2}{*}{ Total } & \multirow[b]{2}{*}{$r$} & \multirow[b]{2}{*}{$p$} \\
\hline & Kurang & Cukup & Baik & & & \\
\hline Rendah & $\begin{array}{c}11 \\
(100 \%)\end{array}$ & $\begin{array}{c}0 \\
(0 \%)\end{array}$ & $\begin{array}{c}0 \\
(0 \%)\end{array}$ & $\begin{array}{c}11 \\
(100 \%)\end{array}$ & 0,271 & 0,000 \\
\hline Sedang & $\begin{array}{c}4 \\
(36,4 \%)\end{array}$ & $\begin{array}{c}6 \\
(54,5 \%)\end{array}$ & $\begin{array}{c}1 \\
(9,1 \%)\end{array}$ & $\begin{array}{c}11 \\
(100 \%)\end{array}$ & & \\
\hline Tinggi & $\begin{array}{c}43 \\
(30,3 \%)\end{array}$ & $\begin{array}{c}80 \\
(56,3 \%)\end{array}$ & $\begin{array}{c}19 \\
(13,4 \%)\end{array}$ & $\begin{array}{c}142 \\
(100 \%)\end{array}$ & & \\
\hline Total & 58 & 86 & 20 & 164 & & \\
\hline
\end{tabular}

Sumber: Pengolahan data primer dan data sekunder

Tabel analisis Spearman Rank diatas lemah yang signifikan antara dukungan didapatkan harga koefisien korelasi $=$ orang tua dengan prestasi belajar. 0,271 dengan nilai $\mathrm{p}=0,000$. Hasil analisis Penelitian yang mendukung adalah tersebut menghasilkan penelitian yang berjudul pengaruh kesimpulan bahwa ada hubungan positif motivasi, dukungan orang tua dan asal sekolah terhadap prestasi belajar mata 
pelajaran akuntansi pada siswa kelas II Madrasah Al-Asror Patemon Gunungpati Semarang yang menghasilkan kesimpulan bahwa ada pengaruh yang positif antara motivasi dan dukungan orang tua terhadap prestasi belajar mata pelajaran akuntansi pada siswa kelas II MA Al- Asror Patemon Gunungpati Semarang (Saragih, 2007).

Salah satu faktor yang mempengaruhi prestasi belajar siswa datang dari faktor eksternal yaitu faktor orang tua (Ahmadi dan Supriyono, 2013). Dukungan orang tua dalam pencapaian prestasi belajar meliputi dukungan informasional yaitu pemberi informasi tentang dunia, petunjuk, nasehat dan saran, dukungan penghargaan dan penilaian yaitu sebuah bimbingan umpan balik berupa ungkapan hormat, penghargaan atas halhal positif dan dorongan untuk terus menghadapi kehidupan, dukungan instrument yang berupa sumber pertolongan praktis dan konkrit seperti alat tulis, buku penunjang, ruang belajar, lampu penerangan, dana, dan sarana pendukung lainnya yang berkaitan dengan proses belajar, dukungan emosional yaitu berupa pemberian keamanan dan kedamaian untuk istirahat dan pemulihan serta membantu penguasaan terhadap emosi yang berupa empati, perhatian dan

kepedulian terhadap yang diberikan untuk anggota keluarga yang ada, ketenangan dalam proses belajar anak dan kenyamanan (Saragih, 2007., Friedman, 2010).

Kasih sayang dari orang tua, perhatian atau penghargaan akan menimbulkan mental yang sehat bagi anak. Kekurangan kasih sayang, sikap keras dan kejam, acuh tak acuh akan menimbulkan emosional insequirity sehingga anak akan mengalami kesulitan belajar. yang berakibat terhadap hasil prestasi belajarnya kelak Bimbingan atau contoh dari orang tua merupakan contoh terdekat dari anakanaknya dalam membantu proses pendidikan anak (Ahmadi dan Supriyono, 2013). Penelitian yang dilakukan oleh peneliti menggunakan responden remaja awal. Masa remaja masih bagian dari keluarga, secara ekonomi masih tergantung dengan orang tua baik dalam proses belajar di sekolah maupun dalam pemenuhan kebutuhan lainnya (Hurlock, 2013, Dalyono, 2015).

Dukungan orang tua yang berupa material digunakan untuk biaya pendidikan serta melengkapi peralatan dan perlengkapan belajar terkait dengan fasilitas belajar. Dukungan informasional dari orang tua dalam pemberian petunjuk, saran, arahan dan bimbingan sangat diperlukan bagi siswa dalam membantu pemecahan masalah 
yang terkait dengan dunia pendidikan agar perencanaan masa depan siswa lebih terarah dan jelas. Dukungan dukungan penghargaan dan penilaian yaitu sebuah bimbingan umpan balik berupa ungkapan hormat, penghargaan atas hal-hal positif dan dorongan untuk terus menghadapi kehidupan sehingga siswa lebih semangat dalam meraih suatu prestasi. Dukungan emosi diberikan kepada siswa berupa pemberian empati dan kepedulian kepada siswa agar siswa bisa mengelola emosinya saat prestasi menurun maupun meningkat (Saragih, 2007., Fayumbo, 2011).

Penelitian yang dilakukan oleh peneliti menunjukkan bahwa pada dukungan orang tua yang rendah berdampak pada nilai rapor 11 siswa kurang dan tidak terdapat siswa yang memiliki nilai rapor cukup serta baik. Tetapi hasil penelitian juga menunjukkan bahwa pada dukungan orang tua yang tinggi masih terdapat siswa yang nilai rapornya kurang yang berjumlah 43 siswa (74,1\% dari jumlah $100 \%$ dari nilai rapor yang kurang). Hal ini dikarenakan dari hasil penelitian ternyata ada faktor lain yang mempengaruhi prestasi belajar siswa yang berupa IQ dan gaji orang tua dengan tingkat korelasi yang lemah pula.

b. Analisis Hubungan Karakteristik Responden dengan Prestasi Belajar Siswa Kelas VIII di SMP Negeri 6 Yogyakarta.

Tabel 7 menunjukkan hasil uji Spearman Rank untuk mengetahui hubungan antara intelegensi dengan prestasi belajar. Tingkat kepercayaan 99 $\%$ menunjukkan koefisien korelasi = 0,229 dan $p=0,000$ sehingga dapat ditarik kesimpulan bahwa ada hubungan positf dan lemah antara intelegensi dengan prestasi belajar siswa. Hasil positif dari korelasi di atas menunjukkan bahwa semakin tinggi intelegensi maka prestasi belajar semakin tinggi juga.

Tabel 7. Hubungan antara Intelegensi dengan Prestasi Belajar Siswa Kelas VIII di SMP Negeri 6 Yogyakarta $(n=164)$

\begin{tabular}{ccccccc}
\hline \multirow{2}{*}{ Intelegensi } & \multicolumn{5}{c}{ Nilai rapor } & \multicolumn{2}{c}{ Total } & $\mathrm{r}$ & $\mathrm{P}$ \\
\cline { 2 - 6 } Sedang & Kurang & Cukup & Baik & & & 0,000 \\
& 9 & 5 & 0 & 14 & 0,341 & \\
\hline Pandai & 37 & $(35,7 \%)$ & $(0 \%)$ & $(100 \%)$ & & \\
& $(41,1 \%)$ & $(53,3 \%)$ & $(5,6 \%)$ & $(100 \%)$ & \\
\hline Cerdas & 12 & 32 & 15 & 59 & & \\
& $(20,3 \%)$ & $(54,2 \%)$ & $(25,4 \%)$ & $(100 \%)$ & &
\end{tabular}




\begin{tabular}{ccccc}
\hline Sangat cerdas & 0 & 1 & 0 & 1 \\
& $(0 \%)$ & $(100 \%)$ & $(0 \%)$ & $(100 \%)$ \\
\hline
\end{tabular}

Sumber: Pengolahan data sekunder

Faktor intern yang mempengaruhi prestasi belajar dilihat dari aspek kecerdasan, minat, bakat, motivasi dan fisiologis individu (Soetjiningsih, 2016). Seseorang yang memiliki IQ tinggi akan mudah belajar dan hasil belajarnya baik sedangkan seseorang yang memiliki IQ rendah akan mengalami kesukaran dalam belajar sehingga prestasi belajarpun akan rendah pula (Kadir dkk, 2017).

Tabel 8. Hubungan antara Jenis Kelamin dengan Prestasi Belajar Siswa Kelas VIII di SMP Negeri 6 Yogyakarta $(n=164)$

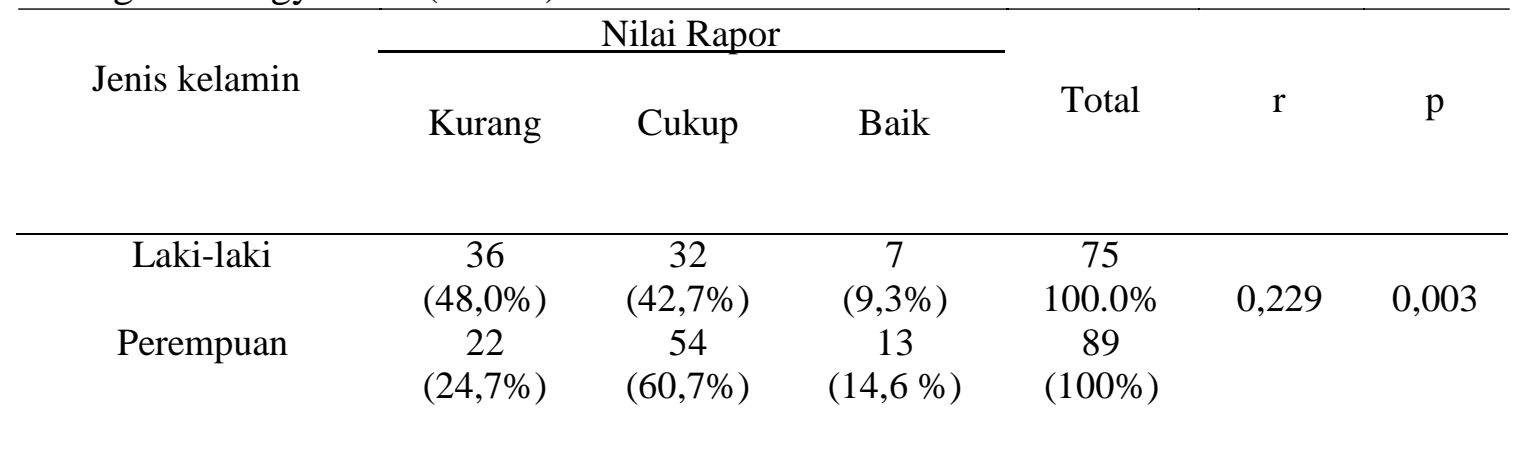

Sumber: Pengolahan data primer dan sekunder

Tabel 8 menunjukkan hasil uji Spearman Rank dengan Tingkat kepercayaan $99 \%$ menunjukkan harga $\mathrm{r}=0,229$ dan $\mathrm{p}=$ 0,003 yang dapat ditarik kesimpulan bahwa ada hubungan positif dan lemah antara jenis kelamin dengan prestasi belajar siswa. Analisis tersebut diinterpretasikan bahwa siswa perempuan cenderung memiliki nilai prestasi belajar yang lebih tinggi daripada siswa laki-laki. Faktor intern yang mempengaruhi prestasi belajar dilihat dari aspek psikologis yaitu kecerdasan, minat, bakat, motivasi dan dari aspek fisiologis individu yaitu kondisi jasmaniah/fisik (Ahmadi dan Supriyono, 2013). Kesehatan jasmani saat sehat dan sakit mempengaruhi kegairahan dalam belajar dan mengakibatkan ada pengaruh terhadap prestasi belajar (Fayumbo, 2011). 
Tabel 9. Hubungan antara Umur dengan Prestasi Belajar Siswa Kelas VIII di SMP Negeri 6 Yogyakarta $(n=164)$

\begin{tabular}{|c|c|c|c|c|c|c|}
\hline \multirow{2}{*}{ Umur } & \multicolumn{3}{|c|}{ Nilai rapor } & \multirow{2}{*}{ Total } & \multirow{2}{*}{$\mathrm{r}$} & \multirow{2}{*}{$\mathrm{P}$} \\
\hline & Kurang & Cukup & Baik & & & \\
\hline \multirow[t]{2}{*}{12} & 0 & 2 & 1 & 3 & \multirow[t]{6}{*}{$-0,93$} & \multirow[t]{6}{*}{0,235} \\
\hline & $(0 \%)$ & $(66,7 \%)$ & $(33,3 \%)$ & & & \\
\hline \multirow[t]{2}{*}{13} & 18 & 27 & 8 & 53 & & \\
\hline & $(34 \%)$ & $(50,9 \%)$ & $(15,1 \%)$ & & & \\
\hline \multirow[t]{2}{*}{14} & 38 & 55 & 11 & 104 & & \\
\hline & $(36,5 \%)$ & $(52,9 \%)$ & $(10,6 \%)$ & & & \\
\hline \multirow[t]{2}{*}{15} & 2 & 2 & 0 & 4 & & \\
\hline & $(50 \%)$ & $(50 \%)$ & $(0 \%)$ & (100) & & \\
\hline
\end{tabular}

Sumber: Pengolahan data sekunder.

Tabel 9 menunjukkan harga $r=-0,93$ dan $\mathrm{p}=0,235$. Hasil analisis tersebut disimpulkan bahwa tidak terdapat hubungan antara umur responden dengan prestasi belajar belajar siswa.

Usia pada tahap remaja awal ini keinginan dalam berprestasi masih belum stabil dan cenderung mengikuti teman sebayanya dalam orientasi prestasi di bidang tertentu yang memberikan kepuasan dan ketenaran. Prestasi belajar di kalangan remaja awal mencakup bidangbidang tertentu di kelompok sebayanya. Para remaja ini cenderung bercita-cita tinggi dan tidak realistis sehingga tidak mencapai kepuasan dalam berprestasi. Sehingga pada usia ini para remaja awal masih belum stabil dalam orientasi prestasi akademik (Saragih, 2007., Sulastri, 2007). Faktor intern mempengaruhi prestasi belajar dilihat dari aspek psikologis yang meliputi kecerdasan, minat, bakat, motivasi dan dari aspek fisiologis individu. Sedangkan faktor ekstern terdiri dari keadaan sosial salah satunya datang dari orang tua dan keadaan non sosial (Soetjiningsih, 2016). 
c. Analisis Hubungan Karakteristik Orang Tua Responden dengan Prestasi Belajar Siswa

Kelas VIII di SMP Negeri 6 Yogyakarta.

Tabel 10. Hubungan antara Gaji Orang tua dengan Prestasi Belajar Siswa Kelas VIII di SMP Negeri 6 Yogyakarta $(n=164)$

\begin{tabular}{|c|c|c|c|c|c|c|}
\hline \multirow[b]{2}{*}{ Gaji } & \multicolumn{3}{|c|}{ NILAIRAPOR } & \multirow[b]{2}{*}{ Total } & \multirow[b]{2}{*}{$\mathrm{r}$} & \multirow[b]{2}{*}{$\mathrm{p}$} \\
\hline & Kurang & cukup & Baik & & & \\
\hline$<\operatorname{Rp} 500.000,00$ & $\begin{array}{c}8 \\
(66,7 \%)\end{array}$ & $\begin{array}{c}4 \\
(33,3 \%)\end{array}$ & $\begin{array}{c}0 \\
(0 \%)\end{array}$ & $\begin{array}{c}12 \\
(100 \%)\end{array}$ & 0,201 & 0,01 \\
\hline $\begin{array}{l}\text { Rp } 500.000,00 \leq \\
\operatorname{Rp} 1.000 .000,00\end{array}$ & $\begin{array}{c}11 \\
(40,7 \%)\end{array}$ & $\begin{array}{c}15 \\
(55,6 \%)\end{array}$ & $\begin{array}{c}1 \\
(3,7 \%)\end{array}$ & $\begin{array}{c}27 \\
(100 \%)\end{array}$ & & \\
\hline $\begin{array}{l}>\operatorname{Rp} 1.000 .000,00 \\
\leq \operatorname{Rp} 2.000 .000,00\end{array}$ & $\begin{array}{c}14 \\
(31,1 \%)\end{array}$ & $\begin{array}{c}27 \\
(60 \%)\end{array}$ & $\begin{array}{c}4 \\
(89 \%)\end{array}$ & $\begin{array}{c}45 \\
(100 \%)\end{array}$ & & \\
\hline $\begin{array}{l}>\operatorname{Rp} 2.000 .000,00 \\
\leq \operatorname{Rp} 3.000 .000,00\end{array}$ & $\begin{array}{c}7 \\
(35 \%) \\
\end{array}$ & $\begin{array}{c}12 \\
(60 \%)\end{array}$ & $\begin{array}{c}1 \\
(5 \%)\end{array}$ & $\begin{array}{c}20 \\
(100 \%)\end{array}$ & & \\
\hline $\begin{array}{l}>\operatorname{Rp} 3.000 .000,00 \\
\leq \operatorname{Rp} 4.000 .000,00\end{array}$ & $\begin{array}{c}4 \\
(20 \%) \\
\end{array}$ & $\begin{array}{r}15 \\
(75 \%) \\
\end{array}$ & $\begin{array}{c}1 \\
(5 \%) \\
\end{array}$ & $\begin{array}{c}20 \\
(100 \%) \\
\end{array}$ & & \\
\hline $\begin{array}{l}>\operatorname{Rp} 4.000 .000,00 \\
\leq \operatorname{Rp} 5.000 .000,00\end{array}$ & $\begin{array}{c}6 \\
(25 \%)\end{array}$ & $\begin{array}{c}10 \\
(417 \%)\end{array}$ & $\begin{array}{c}8 \\
(33,3 \%)\end{array}$ & $\begin{array}{c}24 \\
(100 \%)\end{array}$ & & \\
\hline$>\operatorname{Rp} 5.000 .000,00$ & $\begin{array}{c}8 \\
(50 \%)\end{array}$ & $\begin{array}{c}3 \\
(18,8 \%)\end{array}$ & $\begin{array}{c}5 \\
(31,3 \%)\end{array}$ & $\begin{array}{c}16 \\
(100 \%)\end{array}$ & & \\
\hline
\end{tabular}

Sumber: Pengolahan data sekunder

Tabel 10 menunjukan hasil analisis Uji Spearman Rank dengan tingkat kesalahan $1 \%$ tentang hubungan gaji orang tua responden dengan prestasi Belajar Siswa yang menghasilkan nilai koefisien korelasi 0,201 dan $\mathrm{p}=0,01$. Kesimpulannya bahwa terdapat hubungan positif lemah antara jumlah gaji orang tua dengan prestasi belajar siswa kelas VIII di SMP Negeri 6 Yogyakarta yang artinya semakin banyak jumlah gaji maka prestasi belajar siswa semakin tinggi pula.
Secara mikro sekolah membutuhkan uang dan untuk berprestasi membutuhkan sarana dan prasarana (Michaelowa, 2002., Saragih, 2007). Keadaan ekonomi yang kurang akan menimbulkan kurangnya alat-alat belajar, kurangnya biaya yang disediakan oleh orang tua dan tidak memiliki tempat belajar yang baik sehingga menghambat kemajuan belajar anak (Fayumbo, 2011).

Status sosial ekonomi memiliki hubungan yang signifikan dengan prestasi belajar. Keadaan ekonomi yang miskin 
akan menimbulkan kurangnya alat-alat belajar, kurangnya biaya yang disediakan oleh orang tua dan tidak memiliki tempat belajar yang baik sehingga menghambat belajar anak yang berdampak terhadap hasil belajar (Saragih, 2007). Pendidikan anak memerlukan biaya, keluarga dengan latar belakang penghasilan kurang akan mengalami kesulitan memenuhi kebutuhan berbagai macam kebutuhan belajar, tempat untuk belajar yang memadai yang merupakan salah satu terlaksananya belajar yang efektif dan efisien dalam pencapaian prestasi belajar anak (Shalahuddin, 2012).

Tabel 11.1. Hubungan antara Pendidikan Ayah dengan Prestasi Belajar Siswa Kelas VIII di SMP Negeri 6 Yogyakarta $(n=164)$

\begin{tabular}{|c|c|c|c|c|c|c|}
\hline \multirow[b]{2}{*}{ Pendidikan Ayah } & \multicolumn{3}{|c|}{ NILAIRAPOR } & \multirow[b]{2}{*}{ Total } & \multirow[b]{2}{*}{$\mathrm{r}$} & \multirow[b]{2}{*}{$\mathrm{p}$} \\
\hline & Kurang & cukup & Baik & & & \\
\hline \multirow[t]{2}{*}{ SD } & 3 & 4 & 2 & 9 & \multirow[t]{9}{*}{0,012} & \multirow[t]{9}{*}{0,881} \\
\hline & $(33,3 \%)$ & $(44,4 \%)$ & $(22,2)$ & $(100 \%)$ & & \\
\hline \multirow[t]{2}{*}{ SMP } & 3 & 6 & 0 & 9 & & \\
\hline & $(33,3 \%)$ & $(66,7 \%)$ & $(0 \%)$ & $(100 \%)$ & & \\
\hline SMA & $\begin{array}{c}16 \\
(36,4 \%)\end{array}$ & $\begin{array}{c}25 \\
(56,8 \%)\end{array}$ & $\begin{array}{c}3 \\
(6,8 \%)\end{array}$ & $\begin{array}{c}44 \\
(100 \%)\end{array}$ & & \\
\hline Diploma & $\begin{array}{c}5 \\
(26,3)\end{array}$ & $\begin{array}{c}11 \\
(57,9 \%)\end{array}$ & $\begin{array}{c}3 \\
(15,8 \%)\end{array}$ & $\begin{array}{c}19 \\
(100 \%)\end{array}$ & & \\
\hline S1 & $\begin{array}{c}22 \\
(35,5 \%)\end{array}$ & $\begin{array}{c}33 \\
(53,2)\end{array}$ & $\begin{array}{c}7 \\
(11,3 \%)\end{array}$ & $\begin{array}{c}62 \\
(100 \%)\end{array}$ & & \\
\hline $\mathrm{S} 2$ & $\begin{array}{c}8 \\
(44,4 \%)\end{array}$ & $\begin{array}{c}6 \\
(33,3 \%)\end{array}$ & $\begin{array}{c}4 \\
(22,2 \%)\end{array}$ & $\begin{array}{c}18 \\
(100 \%)\end{array}$ & & \\
\hline S3 & $\begin{array}{c}1 \\
(33,3 \%)\end{array}$ & $\begin{array}{c}1 \\
(33,3 \%)\end{array}$ & $\begin{array}{c}1 \\
(33,3 \%)\end{array}$ & $\begin{array}{c}3 \\
(100 \%)\end{array}$ & & \\
\hline
\end{tabular}

Sumber: Pengolahan data sekunder

Tabel 11.1 di atas menunjukkan hasil uji Spearman Rank untuk mengetahui hubungan antara pendidikan ayah dengan prestasi belajar siswa. Tingkat kepercayaan $99 \%$ menunjukkan harga $r=0,012$ dan $p=0,081$. Hasil analisis tersebut bisa diambil suatu kesimpulan bahwa tidak terdapat hubungan antara pendidikan ayah dengan prestasi belajar belajar siswa. 
Tabel 11.2. Hubungan antara Pendidikan Ibu dengan Prestasi Belajar Siswa Kelas VIII di SMP Negeri 6 Yogyakarta $(n=164)$

\begin{tabular}{|c|c|c|c|c|c|c|}
\hline \multirow[b]{2}{*}{ Pendidikan Ibu } & \multicolumn{3}{|c|}{ NILAIRAPOR } & \multirow[t]{2}{*}{ Total } & \multirow[t]{2}{*}{$\mathrm{r}$} & \multirow[t]{2}{*}{$\mathrm{p}$} \\
\hline & Kurang & cukup & Baik & & & \\
\hline SD & $\begin{array}{c}5 \\
(38,5 \%)\end{array}$ & $\begin{array}{c}7 \\
(53,8 \%)\end{array}$ & $\begin{array}{c}1 \\
(7,7 \%)\end{array}$ & $\begin{array}{c}13 \\
(100 \%)\end{array}$ & 0,097 & 0,217 \\
\hline SMP & $\begin{array}{c}2 \\
(33,3 \%)\end{array}$ & $\begin{array}{c}2 \\
(33,3 \%)\end{array}$ & $\begin{array}{c}2 \\
(33,3 \%)\end{array}$ & $\begin{array}{c}6 \\
(100 \%)\end{array}$ & & \\
\hline SMA & $\begin{array}{c}21 \\
(42,9 \%)\end{array}$ & $\begin{array}{c}26 \\
(53,1 \%)\end{array}$ & $\begin{array}{c}2 \\
(4,1 \%)\end{array}$ & $\begin{array}{c}49 \\
(100 \%)\end{array}$ & & \\
\hline Diploma & $\begin{array}{c}9 \\
(33,3 \%)\end{array}$ & $\begin{array}{c}13 \\
(48,1 \%)\end{array}$ & $\begin{array}{c}5 \\
(18,5 \%)\end{array}$ & $\begin{array}{c}27 \\
(100 \%)\end{array}$ & & \\
\hline S1 & $\begin{array}{c}17 \\
(27,9 \%)\end{array}$ & $\begin{array}{c}36 \\
(59 \%)\end{array}$ & $\begin{array}{c}8 \\
(13,1 \%)\end{array}$ & $\begin{array}{c}61 \\
(100 \%)\end{array}$ & & \\
\hline S2 & $\begin{array}{c}2 \\
(40 \%)\end{array}$ & $\begin{array}{c}1 \\
(20 \%)\end{array}$ & $\begin{array}{c}2 \\
(40 \%)\end{array}$ & $\begin{array}{c}5 \\
(100 \%)\end{array}$ & & \\
\hline S3 & $\begin{array}{c}2 \\
(66,7 \%)\end{array}$ & $\begin{array}{c}1 \\
(33,3 \%)\end{array}$ & $\begin{array}{c}0 \\
0 \%\end{array}$ & $\begin{array}{c}3 \\
(100 \%)\end{array}$ & & \\
\hline
\end{tabular}

Sumber : Pengolahan data sekunder

Tabel 11.2 di atas menunjukkan hasil uji Spearman Rank untuk mengetahui hubungan antara pendidikan Ibu dengan prestasi belajar siswa. Tingkat kepercayaan $99 \%$ menunjukkan harga $\mathrm{r}=$ 0,097 dan $p=0,217$. Hasil analisis tersebut bisa diambil suatu kesimpulan bahwa tidak terdapat hubungan antara pendidikan ibu dengan prestasi belajar belajar siswa.

$$
\text { Hasil analisis hubungan }
$$
pendidikan orang tua dengan prestasi belajar siswa sesuai dengan tabel $11 \mathrm{di}$ atas bertentangan dengan teori yang mengatakan bahwa orang tua yang berpendidikan akan lebih mengerti jenis kondisioning yang lebih tepat untuk mendorong prestasi belajar anaknya (Syah, 2008). Selain itu hasil penelitian tentang hubungan pendidikan orang tua dengan prestasi belajar anak juga bertentangan dengan teori yang mengatakan bahwa tinggi rendahnya pendidikan orang tua juga sangat mempengaruhi prestasi belajar anak. Anak yang kedua orang tuanya berpendidikan, maka prestasi belajar pada pelajaran Matematika dan bahasa Perancis lebih tinggi dibandingkan anak yang kedua orang tuanya tidak berpendidikan (Friedman, 2010., Hurlock, 2013). Hal ini dikarenakan masih terdapat faktor lain yang mempengaruhi Prestasi belajar yang dicapai individu yang merupakan hasil interaksi antara faktor internal individu 
maupun faktor eksternal individu

(Winkel, 2007).

\section{KESIMPULAN}

Berdasarkan hasil penelitian

mengenai hubungan dukungan orang tua dengan prestasi belajar siswa kelas VIII di SMP Negeri 6 Yogyakarta serta pembahasan yang peneliti lakukan maka dapat ditarik kesimpulan yaitu:

1. Prestasi belajar siswa kelas VIII SMP Negeri 6 Yogyakarta mayoritas dengan kategori Cukup

2. Dukungan orang tua siswa kelas VIII SMP Negeri 6 Yogyakarta mayoritas dengan kategori tinggi

3. Terdapat hubungan yang positif dan lemah antara dukungan orang tua dengan prestasi belajar siswa kelas VIII di SMP Negeri 6 Yogyakarta.

4. Terdapat hubungan yang positif dan lemah antara IQ responden dengan prestasi belajar siswa kelas VIII di SMP Negeri 6 Yogyakarta

5. Terdapat hubungan yang negatif dan lemah antara jenis kelamin responden dengan prestasi belajar siswa kelas VIII di SMP Negeri 6 Yogyakarta

6. Tidak terdapat hubungan antara umur responden dengan prestasi belajar siswa kelas VIII di SMP Negeri 6 Yogyakarta
7. Terdapat hubungan yang positif dan lemah antara gaji orang tua responden dengan prestasi belajar siswa kelas VIII di SMP Negeri 6 Yogyakarta

8. Tidak terdapat hubungan antara pendidikan orang tua responden dengan prestasi belajar siswa kelas VIII di SMP Negeri 6 Yogyakarta

\section{DAFTAR PUSTAKA}

Ahmadi, A dan Supriono. 2013. W. Psikologi Belajar. Jakarta: PT Rineka Cipta

Dahl, G. \& Lochner, L. 2005. The Impact of Family Income on Child Achivement. University of Western Ontario. [cited 23 Desember 2016]. Available from: http://nces.ed.gov/

Dahlan S. 2014. Statistik Untuk Kedokteran dan Kesehatan. Deskriptif, Bivariat dan Multivariat dilengkapi Aplikasi Menggunakan SPSS, edisi 6. Jakarta: Epidemiologi Indonesia

Dalyono, M. 2015. Psikologi Pendidikan, edisi 8. Jakarta: Rineka Cipta.

Departemen Pendidikan Nasional Republik Indonesia. 2008. Program Pembangunan Nasional. Jakarta.

Fayumbo G. A. 2011. Student Related Variables as Predictors of Academic Achivement Among Some Undergraduate Psychology Students in Barbados. US-China Education 
Friedman, M. Keperawatan Keluarga. 2010. Jakarta: EGC

Hasbullah. Dasar-dasar Ilmu Pendidikan. 2012. Jakarta: PT Raja Grafindo Persada, 2001.

Peters, M., Seeds, K., Goldstein, A. \& Coleman, N. 2007. Parental Involvement in Children's Education. [cited 23 Desember 2016]. Available from: URL: http://nces.ed.gov/pubserach/pub sinfo.asp?

Hurlock, B., E. 2013. Psikologi Perkembangan Suatu Pendekatan Sepanjang Rentang Kehidupan, edisi 5 terjemahan. Jakarta : Erlangga.

Kadir A, Fauzi A, Yulia, Bachaqi, Kurnianto R dan Rosmiati. 2017. Dasar-dasar Kependidikan. Jakarta: Gramedia.

Legawati. 2004. Hubungan Dukungan Sosial Keluarga dengan Prestasi Belajar Mahasiswa Jurusan Angkatan IV Semester VI Poltekes Palangkaraya, Skripsi. Fakultas Kedokteran Universitas Gajah Mada Yogyakarta. Naskah Tidak Dipublikasikan.

Michaelowa, K. 2002. Returns Education in Low Income Countries: Evidencefor Africa. Paper Presented at Annual Meeting of the German Economic Association. Hamburg: Institusi for International Economics.

Saragih, L. S. 2007. Hubungan Karakteristik Sosial Orang Tua dengan kekekrasan pada Anak dalam Keluarga dengan Prestasi Belajar di Kota Medan, Tesis. Fakultas Kedokteran Universitas
Gajah Mada. Naskah Dipublikasikan. Available from: http://infolib.med.ugm/

Shalahuddin, M. 2012. Pengantar Psikologi Pendidikan. Surabaya: Bina Ilmu.

Soetjiningsih, Hartini K \& Nurani N. 2016. Korelasi Derajat Obesitas dengan Prestasi Belajar Siswa Sekolah Dasar. [cited 26 Februari 2017]. Available From: http//www.google.com//

Sugiyono. 2016. Metode Penelitian Kuantitatif, Kualitatif dan R\& D. Alfabeta: Bandung

Sulastri, T. 2007. Pengaruh Obesitan terhadap Prestasi Belajar pada Siswa SMP di Kota Yogyakarta, Tesis. Fakultas Kedokteran Universitas Gajah Mada.

Syah, M. 2008. Psikologi Pendidikan dengan Pendekatan Baru. Bandung : PT Remaja Rosdakarya.

Winkel, W. S. Psikologi Pengajaran. 2007. Yogyakarta: Media Abadi. 